\title{
Aspe Armella, V. Aristóteles y Nueva España. (2018). UASLP. 449 pp.
}

No siempre es posible comentar un libro generoso como este de Virginia Aspe Armella, un trabajo de largo aliento que nos permite asentar estados de la cuestión sobre temas nodales del pensamiento hispánico. Se trata de un tratado monográfico que recuerda la magistral obra de Marcel Bataillon, su Erasmo y España (1937), no sólo en cuanto al aporte y sistematización de información, no sólo por sus interpretaciones más o menos agudas y documentadas, sino sobre todo porque -como aquél- enseña a pensar problemas. Este libro trata, desde la historia de las ideas, el lugar de Aristóteles en el pensamiento filosófico, político y literario de la Nueva España, ofreciéndonos una visión de conjunto que resulta reveladora del lugar central del pensamiento aristotélico en autores señeros de las letras novohispanas, desde Bartolomé de las Casas y Sahagún hasta Clavijero, pasando por los monumentos de Sor Juana Inés de la Cruz y Carlos de Sigüenza y Góngora.

A nadie debería extrañar esta centralidad de Aristóteles en obras producidas en un sitio tan distante de los centros de cultura del momento. Porque la Nueva España se insertó desde un principio, de manera directa, en un proyecto cultural panhispánico de largo aliento y de profundas raíces occidentales; además, recuérdese que el propio pensamiento aristotélico tuvo por vocación la universalidad, desde que el Estagirita configuró un sistema reflexivo sobre la realidad cuyo sino fue la trashumancia. De este modo, el hecho de que un griego siga enseñando más de mil años después de su tiempo, que haya enseñado a los novohispanos a pensar el mundo y su circunstancia, no hace otra cosa que realizar su universalidad esencial.

De hecho, como se sabe, a España Aristóteles había llegado no por los romanos sino desde el mundo árabe, que había conservado el saber helénico en los acervos documentales heredados por el Islam de los antiguos dominios de Alejandro; así, entre los siglos XI y XII, el filósofo persa Avicena y el filósofo hispanoárabe Averroes, comentarían docta y elegantemente diversas obras de Aristóteles, como la Poética y la Retórica. Y es que aun cuando el redescubrimiento renacentista de la Poética se data en 1498, gracias a la traducción latina que de ella realizó Giorgio Valla y gracias también a la edición del texto griego que publicó Aldo Manucio (Venecia, 1508-1509), la Escuela de Traductores de Toledo ya había llevado a cabo las primeras versiones al latín tanto de la Poética como de la Retórica, partiendo de aquellas versiones árabes de Averroes y Avicena. 
Tampoco debe sorprender que aquí yo considere que sean la Retórica y la Poética (junto con las obras lógicas de Aristóteles) los textos inductores del pensamiento crítico y creativo en Nueva España, desde su lugar central en el antiguo sistema pedagógico del trivium de las artes liberales, no tanto como textos sustantivos de las argumentaciones aristotélicas sino sobre todo como herramientas constructoras de la propia argumentación. Y es que estos textos no consisten, en absoluto, en simples aportes de reglas de pensamiento o de dicción, sino que significan la construcción sistemática de una feliz obsesión que penetraría el mundo medieval y fertilizaría todos los siglos posteriores: la obsesión por la verdad, así como la construcción de los principios fundamentales de la argumentación; con ambas herramientas, el Estagirita fue capaz de defender la retórica de los terribles vituperios vertidos por Platón contra ella, sobre todo en el Gorgias. Recuérdese cómo, en el libro primero de su Retórica, Aristóteles trataría el valor del argumento en los discursos persuasivos como un aspecto fundamental de su definición del arte retórico, cuestionando las consideraciones platónicas sobre la inferioridad de la retórica frente a la dialéctica justamente a partir de los modos en que en cada una de ellas se demuestran diferenciadamente las afirmaciones.

Pero fue en la Poética en que esta reflexión sobre la verdad tomó vuelos con alas que no han sido todavía igualadas, produciendo el feliz concepto poético de "verosimilitud", fundamental para la resistencia de la literatura frente a los constantes asedios de la religión, resistencia paradigmática (dicho sea de paso) en sor Juana Inés de la Cruz como en Cervantes. Así, en el marco de la intolerancia que la preceptiva retórica cristiana había mostrado frente al uso de la ficción, ya en la copiosa producción preceptiva originada en la reforma lateranense se había pretendido ajustar la ficción poética a la teología a fin de salvarla de la condición de mentira, de modo que el único espacio donde podría circular con libertad fue en la alegoría; valoración negativa del arte poético que para Marcelino Menéndez Pelayo no fue en modo alguno una circunstancia lamentable, pues en su opinión "esta desestimación suya casi debe agradecérsele [...] puesto que, gracias a ella, emancipaban el arte de la pedantesca tiranía de lo útil y de lo científico" (Menéndez Pelayo, 1974, t. I, p. 618).

El resultado de esta censura sería, para gozo de don Marcelino, una toma de posición contraria de parte de quienes se sintieron obligados a defender el arte poético, y que buscaron hacerlo con base justamente 
en la negación del pecado que se le imputaba: su poca cercanía a la verdad, defensa que García Berrio llama "uno de los tópicos más firmemente activos del Renacimiento" (García Berrio, 1977, pp. 166). Tópico particularmente cultivado por los jesuitas novohispanos, quienes en los preceptos oratorios consignados en su Ratio studiorum (un método didáctico inspirado en los progymnasmata que se incluían en la enseñanza del trivium), reconocían la autoridad de "Cicerón, la Retórica de Aristóteles (y, si se quiere, su Poética) y Quintiliano". ${ }^{1}$ Esta fortísima presencia explica no sólo el cariz aristotélico de la oratoria sagrada jesuítica, sino incluso de la obra poética y científica de algunos de sus hijos más preclaros: Sor Juana (a partir de los preceptos de su confesor), Sigüenza y Clavijero.

Como puede apreciarse, estos apuntes se limitan a reflejar las lecturas de un literato descarriado en lugar de hacer justicia integral al aporte del Estagirita al pensamiento novohispano. Sin embargo, justamente por ello es que nos viene tan bien este libro de Virginia Aspe, porque ilustra de un modo erudito y notable las formas en que el pensamiento aristotélico estuvo presente en las Indias, incluso desde las disputas filosófico-políticas iniciales de nuestra historia: la de Valladolid (15501551) entre Bartolomé de las Casas y Ginés de Sepúlveda, ubicadas en el corazón mismo de la justificación política e ideológica de la Conquista; presencia, dicho sea de paso, que posee una circunstancia singularísima perfectamente explicada por la autora: el hecho de que las dos partes de aquella controversia fundadora usasen categorías aristotélicas.

Esa también es una característica fundamental del pensamiento aristotélico y, en general, del pensamiento clásico: su cercanía esencial con la disputa, no sólo al favorecerla como medio poderoso de construcción de la argumentación, sino incluso como medio de encontrar su lugar en la historia. Recuérdese cómo con el advenimiento del Cristianismo inició una etapa compleja para el desarrollo del pensamiento clásico en Occidente; pues, como se sabe, es a Marciano Capella a quien se atribuye la introducción de las artes clásicas en la Alta Edad Media a partir de su Bodas de Mercurio con la filología, aunque la transición desde los gramáticos de los primeros siglos de nuestra era (como traductores de la cultura greco-latina ante los nuevos usuarios cristianos), pasa por

1 Traduzco de la versión inglesa de Ball, A. R. (1933) en E. A. Fitzpatrick, St. Ignatius and the Ratio Studiorum. McGraw / Hill, p. 208. 
la enorme labor de cristianización de las artes clásicas realizada por los Padres de la Iglesia.

Uno de los aspectos fundamentales de esta transición fue el modo en que los tres estilos retóricos de la Antigüedad (sublime, medio y bajo) fueron ajustados a una nueva noción de discurso y persuasión que, como escribió Auerbach, ahora "no conoce gradaciones temáticas absolutas" (Auerbach, 1969: 38), pues el gran tema cristiano de la Redención no podía ser exclusivo de ningún auditorio ( $\mathrm{y}$, por tanto, de ningún estilo) sino que, por el contrario, debía ser comunicado a todo el mundo. De este modo, el estilo y los temas humildes dejaron con el Cristianismo el significado peyorativo que tuvieron en la retórica clásica, aunque en un principio la mayoría de los paganos cultos siguió considerando ridícula, confusa e incluso repelente la oratoria cristiana.

En respuesta a ello, algunos obispos se lanzaron contra los textos paganos trayendo ecos que podrían considerarse platónicos, al grado de que el IV Concilio de Cartago (419 d.C.) habría prohibido la lectura de estos libros. Así, muchos hombres cultos, al convertirse al cristianismo, se vieron obligados a reaccionar contra la cultura grecorromana, como Lactancio, para quien aquella era "una golosina envenenada" (Murphy, 1986: 61); o bien Gregorio Magno, que había preferido el estudio bíblico y, por tanto, rechazado el de los clásicos, como puede verse en su Regula pastoralis (s. VI) donde fundamenta una preceptiva sin referencias a la Antigüedad.

Jerónimo, en cambio, en su intento por encontrar una solución al dilema, mostraba huellas de un gran conflicto interior, una de ellas en su hermosa Epístola 22 a la virgen de Eustoquio. Después de su conversión, el santo había renunciado a su buena vida en Roma, había dejado todo para hacer penitencia en Jerusalén, menos sus libros, que le seguían sirviendo de solaz y goce estético, hasta que en una visión, al borde de la muerte por una enfermedad, es llamado a cuentas por la continuación de sus lecturas clásicas. Se trata de un relato que tendría fértil y feliz vida en los siglos posteriores, incluso tan tardíos como el XVII, cuando el jesuita novohispano Juan Martínez de la Parra lo usa como ejemplo en una de sus pláticas:

No es menos que el Doctor Máximo, y Padre de las Escrituras S. Jerónimo el que lo refiere, y lo refiere de si mesmo, y asi lo dire con sus palabras mesmas, con que lo cuenta a la Virgen Eustochio. Años ha, le dize, que 
aviendo dexado a Roma, a mi casa, padres, parientes, y amigos, por buscar el Cielo, me retire a Jerusalén, a macerar mi cuerpo en continuos ayunos, por los combites con que antes avia atendido a su regalo. Pero aviendolo dexado por Dios todo, solos mis libros no tuve animo, ni corazon para dexarlos. Era en mi soledad el leer a Ciceron el saynete de mis ayunos, y quando después de largas vigilias, en que con amargas lagrimas de mi corazon procuraba lavar mis passadas culpas, para aliviar algun rato, leyendo a Ciceron me divertia, de aquí vino, que quando passaba a leer en las Divinas Escrituras, aquel estilo tan llano como verdadero, tan sincero como puro, me ponia tedio, me daba en rostro. Miserable de mi, que echaba ya al Sol la que no era culpa sino de mis ojos. Quando he aquí, que con un tabardillo a pocos dias, estando ya a la muerte, de repente arrebatado mi espiritu me halle delante de vn tribunal tan cercado de resplandores, y Magestad, que ni a levantar los ojos me atrevia. Quien eres? Me pregunto aquel Juez Soberano; y yo temblando todo: Señor yo soy Christiano. Mientes, me replico con vna voz terrible; mientes, que tu no eres Christiano, sino Ciceroniano. $\mathrm{Y}$ al punto mandando a sus ministros, que me azotasen, empezaron a descargar sobre mis espaldas terribles azotes, y siendo tales me atormentaban mas los azotes de mi propia conciencia, y clamaba: Señor, ten misericordia de mi. Estas vozes se oian entre los golpes de los azotes, que no cessaban. Hasta que postrados ante el Tribunal, aquellos mesmos Ministros, me recabaron el perdon, con palabra que di, de no leer mas aquellos libros. Testigo es de que no fue sueño, aquel Tribunal tan terrible; y testigos los cardenales, y las llagas, que quedaron en mis espaldas (Martínez, 1691: 12).

Probablemente también Martínez de la Parra, como Sigüenza y Góngora, Clavijero, la propia Sor Juana, lo mismo que los grandes humanistas indianos del siglo XVI: Las Casas o Alonso de la Vera Cruz, entre tantos otros, se habrían sentido en más de una ocasión aristotélicos 
antes que cristianos, desde el lugar central que el pensamiento del Estagirita ocupó en la formación humanística de la época.

En suma, este trabajo de Virginia Aspe enfoca un problema fundamental para la constitución de la cultura novohispana (la religiosa como la política, la jurídica como la filosófica o la poética): el pensamiento aristotélico; y lo hace de un modo paradigmático, no sólo en cuanto a su concepción sino también en cuanto a su disposición, pues -como afirmé al inicio de este texto- se trata de un libro que no se limita a informar sino que ayuda a pensar los problemas, como lo hizo el propio Aristóteles.

\section{Referencias}

Aristóteles (1974). Poética. V. García Yebra (trad.). Gredos.

Aristóteles (2002). Arte Retórica. A. Ramírez (trad.). Universidad Nacional Autónoma de México.

Auerbach, E. (1969). Lenguaje literario y público en la baja latinidad y en la Edad Media. L. López Molina (trad.). Seix-Barral.

Bataillon, M. (1966 [1937]). Erasmo y España. Estudios sobre la historia espiritual del siglo XVI. A. Alatorre (trad.). Fondo de Cultura Económica.

Compañía de Jesús (1933 [1591]). Ratio studiorum. A. R. Ball (trad. al inglés). En E. A. Fitzpatrick. St. Ignatius and the Ratio Studiorum. McGraw / Hill.

García Berrio, A. (1977). Formación de la teoría literaria moderna. Cupsa.

Marciano Capella (2016). Las nupcias de Filología y Mercurio. F. Navarro Antolín (trad.). CSIC.

Martínez de la Parra, J. (1691-1696). Luz de verdades catholicas, y explicacion de la doctrina cristiana, que siguiendo la costumbre de la casa professa de la Compañia de Jesus de México, todos los jueves del año ha explicado en su iglesia el padre Juan Martinez de la Parra, professo de la misma Compañía. Diego Fernández de León.

Murphy, J. (1986). La retórica en la Edad Media. G. Hirata (trad.). Fondo de Cultura Económica.

Manuel Pérez Instituto de Investigaciones Humanísticas Universidad Autónoma de San Luis Potosí 